\title{
Effect of Anti-TNF Therapy on Resistance to Insulin in Patients with Rheumatoid Arthritis
}

\author{
Mario Pérez $^{1 *}$, Raul Ariza ${ }^{2}$, Ruben Asencio ${ }^{1}$, Adolfo Camargo ${ }^{1}$, Heladia Garcia ${ }^{1}$, \\ Miguel Angel Vazquez ${ }^{1}$, Leonor Barile-Fabris ${ }^{1}$
}

${ }^{1}$ UMAE Specialty Hospital "Bernardo Sepulveda” CMNSXXI, IMSS, Mexico City, Mexico; ${ }^{2}$ Hospital Angeles del Pedregal, Mexico City, Mexico.

Email: craulariza@yahoo.com.mx, axel190106@hotmail.com, lbarile@prodigy.net.mx, adolfo_camargo@yahoo.com, hely1802@yahoo.com.mx, vazza78@hotmail.com, *drmariopc@hotmail.com

Received June $6^{\text {th }}, 2013$; revised July $6^{\text {th }}, 2013$; accepted July $14^{\text {th }}, 2013$

Copyright (C) 2013 Raul Ariza et al. This is an open access article distributed under the Creative Commons Attribution License, which permits unrestricted use, distribution, and reproduction in any medium, provided the original work is properly cited.

\begin{abstract}
Objective: To evaluate the effect of anti-TNF therapy on resistance to insulin in patients with rheumatoid arthritis (RA) compared with patients with RA being treated with non-biological DMARDs. Methods: Inactive patients diagnosed with RA (ACR 1987 criteria) (DAS $28<2.6$ ) were included, being treated with anti-tumor necrosis factor inhibitors (anti-TNF) (cases) and non-biological disease-modifying anti-rheumatic drugs (DMARD) (controls), without risk factors for insulin resistance (administration of steroids, body mass index $>25 \mathrm{~kg} / \mathrm{m}^{2}$, diabetes mellitus or use of glucose lowering agents, systemic arterial hypertension or use of anti-hypertensive drugs, triglycerides $>150 \mathrm{mg} / \mathrm{dl}$, hypercholesterolemia $>200 \mathrm{mg} / \mathrm{dl}$, high-density lipoproteins $<40 \mathrm{mg} / \mathrm{dl}$ in men and $<50 \mathrm{mg} / \mathrm{in}$ women, or with lipids lowering agents, waist measurement $>88 \mathrm{~cm}$ in women and $>102 \mathrm{~cm}$ in men). We used HOMA (Homeostasis Model Assessment) to determine insulin resistance in both groups, HOMA being defined as $>1$ and sensitivity to insulin using QUICKI (Insulin Sensitivity Check Index), $\geq 0.38$ being considered as normal. The Mann Whitney U was used for the statistical analysis. Results: A total of 28 patients, 15 being treated with non-biological DMARDs and 13 with antiTNF therapy, were evaluated; $89.7 \%$, of which were women. Average age: 43.5 (range 21 - 62); the average HOMA index of the non-biological DMARD group was 1.58 (range $0.7-5.4$ ), compared with patients treated with anti-TNF therapy, 1.18 (range $0.2-4.3)(\mathrm{P}=0.5)$. The average QUICKI index was 0.36 (range $0.30-0.42)$ in patients treated with non-biological DMARD, compared with 0.37 in patients treated with anti-TNF therapy (range $0.30-0.51)(\mathrm{P}=$ 0.8). Conclusion: Resistance to insulin manifested itself in both groups, although there was a greater trend of less insulin resistance and greater sensitivity in the anti-TNF group; this was probably not statistically significant due to the sample size.
\end{abstract}

Keywords: Anti-TNF; Resistance to Insulin; Rheumatoid Arthritis

\section{Introduction}

Rheumatoid arthritis (RA) is the most common form of chronic inflammatory joint disease that brings about osseous destruction. The inflammatory process causes thickening and hyperplasia of the synovium, which is infiltrated by numerous cells that produce pro-inflammatory cytokines, including IL-1, IL-6 and tumor necrosis factor (TNF) [1]. This inflammation plays an important part in the pathogenesis of atherosclerosis and contributes to the cardiovascular morbidity and mortality found in patients with RA [2]. Cardiovascular disease is twice

"Corresponding author. as common in patients with RA, in comparison with the general population [3].

The increase in insulin resistance is another major risk factor in the development of cardiovascular disease, several methods for evaluating insulin resistance have been developed, of these, homeostasis model assessment (HOMA) has been reported to be unable to evaluate insulin resistance. The quantitative insulin sensitivity check index (QUICKI) has been reported to be a useful marker of insulin resistance. [4]. An increase in insulin resistance has been reported in patients with auto-immune diseases, including patients with RA [5,6]. In a case-control study it was found that insulin resistance of patients with RA 
manifested itself in $88.9 \%$ of patients, compared with just $6.2 \%$ of the controls that consisted of patients with soft tissue disease. There was also a significant association with sub-clinical atherosclerosis evaluated by means of thickening of the intima-media layer of the carotid artery [7].

TNF is a pleiotropic cytokine that plays a pivotal role in the host's response against microorganisms. It is also an important component of the inflammatory path and is over-expressed in the synovial tissue and in serum of patients with RA and on the atherosclerotic plate [3,8]. It has been observed that it contributes to atherogenesis by means of a series of mechanisms: promoting the expression of adhesion molecules in endothelial cells and recruiting and activating inflammatory cells within the arterial wall [9]. Several studies have suggested that TNF may be an important mediator in insulin resistance in animal models $[10,11]$. There is also evidence that overexpression occurs in the adipose tissue and skeletal muscle of patients resistant to insulin $[12,13]$. Loss of weight in obese subjects with insulin resistant leads to a substantial reduction in the expression and secretion of the TNF in association with a decrease in levels of TNF, and the restoring of sensitivity to insulin [14].

Given the effects on inflammation and metabolism, it may be expected that neutralization of the TNF will decrease resistance to insulin and, in turn, decrease cardiovascular risk [15].

Kiortsis et al. did not show any major differences in patients with RA and ankylosing spondylitis treated with Infliximab for six months, in HOMA and QUICKI indices (methods of determining resistance to insulin and sensitivity to insulin, respectively) before and after treatment. Nevertheless, a considerable difference in pre- and post treatment values with anti-TNF [16] was found in patients with higher HOMA and QUICKI indices in basal determinations in a study carried out on 27 patients with RA ( 21 women and 6 men, with an average age of 57.1 and an average DAS 28 of 4.43) with reduction in serum levels of insulin and the HOMA index, after infusion of infliximab [17].

There is still some controversy concerning the role that the anti-TNF block has on resistance to insulin.

\section{Design of the Study}

Cases and controls.

\section{Material and Methods}

Cases included patients of the rheumatology service diagnosed with rheumatoid arthritis according to ACR classification criteria [18], being treated with anti-TNF therapy and with no details of activity (DAS $28<2.6$ ).

Controls comprised inactive patients of the rheuma- tology service diagnosed with rheumatoid arthritis according to ACR classification criteria, being treated with non-biological DMARD not being given anti-TNF therapy, who were paired with cases by gender and age.

The two groups studied did not show any signs of risk that would increase resistance to insulin. Insulin levels were determined using electrochemical luminescence and glucose by enzymatic colorimetric test during fasting, in serum, of both study groups.

The Homeostasis Model Assessment (HOMA) model was used to determine resistance to insulin and sensitivity to insulin using the Insulin Sensitivity Check Index (QUICKI) in both groups.

\section{Statistical Analysis}

The statistical analysis was carried out using a Mann Whitney $\mathrm{U}$ to compare differences in resistance to insulin among the two groups studied. The SPSS 15.0 program was used.

\section{Results}

Twenty-eight patients were included; 13 cases and 15 controls, treated as follows: Case 10 with Etanercept, 2 with Adalimumab and one with Infliximab Controls $86.6 \%$ under Methotrexate, 20\% Leflunomide, 26.6\% Sulfasalazine and $20 \%$ with anti-malariac drugs.

Out of the overall groups, only three were men, who belonged to the anti-TNF, the other $89.7 \%$ being women.

Table 1 shows the baseline demographic characteristics of both groups, age, body mass index (BMI) time evolution of RA in months, time inactivity of RA in months, disease activity score (DAS-28), rheumatoid factor in $\mathrm{UI} / \mathrm{ml}$, waist in $\mathrm{cm}$, cholesterol in $\mathrm{mg} / \mathrm{dl}$, triglycerides in $\mathrm{mg} / \mathrm{dl}$ and HDL-colesterol in $\mathrm{mg} / \mathrm{dl}$, in which there were no statistically significant differences.

The average serum glucose during fasting in the control group was $85 \mathrm{mg} / \mathrm{dl}(41-97)$, while it was $80 \mathrm{mg} / \mathrm{dl}$ (67 - 98) $\mathrm{P}=0.628$ for cases; the average level of serum insulin during fasting in the control group was $9.1 \mathrm{mIU} /$ $\mathrm{ml}(4$ - 25.6), compared with $6 \mathrm{mIU} / \mathrm{ml}(1.1$ - 17.9) for cases, without there being a statistically significant difference $(\mathrm{P}=0.387)$.

On an overall basis, an increase in insulin resistance was observed in both groups of patients, evidenced by an HOMA index greater than 1 , in addition to a decrease in sensitivity to insulin to less than 0.38

In spite of there being a remission of the illness in the control group, most patients (66.6\%) had an HOMA index of greater than 1 and $53 \%$ a QUICKI index less than 0.38 . In the cases group, $53.8 \%$ of patients had an HOMA index greater than 1 and $61.5 \%$ a QUICKI index less than 0.38 .

We did not find a statistically significant difference in 
Table 1. Demographic characteristics of patients with and without anti-TNF therapy.

\begin{tabular}{|c|c|c|c|}
\hline & DMARD N = 15 & ANTI-TNF N = 13 & $\mathbf{P}^{*}$ \\
\hline $\mathrm{Age}^{\&}$, years (range) & $44(21-62)$ & $43(22-58)$ & 0.695 \\
\hline Weight $^{\&}, \mathrm{~kg}$ (range) & $59(44-68)$ & $61(48-70)$ & 0.393 \\
\hline $\mathrm{Size}^{\&}, \mathrm{~cm}$ (range) & $156(149-163)$ & $160(147-168)$ & 0.138 \\
\hline $\mathrm{BMI}^{\&}, \mathrm{~kg} / \mathrm{m}^{2}$ (range) & $24.3(16.9-25)$ & $23.1(20.7-24.8)$ & 0.050 \\
\hline Time of evolution ${ }^{\&}$, months (range) & $6(4-30)$ & $6(1-15)$ & 0.432 \\
\hline Time of inactivity ${ }^{\&}$, months (range) & $5(2-24)$ & $4(1-48)$ & 0.235 \\
\hline Rheumatoid factor ${ }^{\&}, \mathrm{UI} / \mathrm{ml}$ (range) & $78.2(9-553)$ & $66.5(5-632)$ & 0.479 \\
\hline DAS $28^{\&}$ (range) & $2.30(2-2.5)$ & $2.3(1.1-2.5)$ & 0.832 \\
\hline Waist $^{\& \&}, \mathrm{~cm}$ (range) & $85(63-87)$ & $83(71-90)$ & 0.745 \\
\hline Cholesterol $^{\&}, \mathrm{mg} / \mathrm{dl}$ (range) & $162(110$ - 199) & $151(116-194)$ & 0.42 \\
\hline Triglycerides ${ }^{\&}, \mathrm{mg} / \mathrm{dl}$ (range) & $92(71-145)$ & $95(50$ - 111) & 0.419 \\
\hline HDL-colesterol ${ }^{\&}, \mathrm{mg} / \mathrm{dl}$ (rango) & $57(50-80)$ & $55(40-76)$ & 0.196 \\
\hline
\end{tabular}

*Mann-Whitney U; ${ }^{*}$ Average values (range).

insulin resistance, the average HOMA index being 1.58 $(0.7$ - 5.4) in the control group, and $1.18(0.2-4.3)$ on the case group $(\mathrm{P}=0.534)$ (Figure 1).

Likewise, the average QUICKI index in the control group was 0.36 (0.30 - 0.42), compared with 0.37 (0.30 0.51 ) in the case group, without there being a statistically significant difference (Figure 2).

\section{Conclusion}

Resistance to insulin presented itself in both study groups, although there was less resistance to insulin and greater sensitivity in the group being treated with anti-TNF; this was probably not statistically significant due to the sample size.

\section{Discussion}

Two groups of patients with rheumatoid arthritis were selected for the study, who had no risk factor nor any predisposing factor concerning development of resistance to insulin, for example: activity of the disease, as a direct proportional relationship between activity of the disease and resistance to insulin [6] has been observed in some studies. The significant result was that in spite of the disease being in remission, the majority of patients of both groups showed an increase in resistance to insulin and a decrease in sensitivity to insulin.

Kiortsis et al. [16] studied the effect of anti-TNF therapy (Infliximab only) on 28 active patients with rheumatoid arthritis, in other words, they were refractory patients being treated with non-biological DMARDs and prednisone (5 $\mathrm{mg}$ a day). There were no substantial

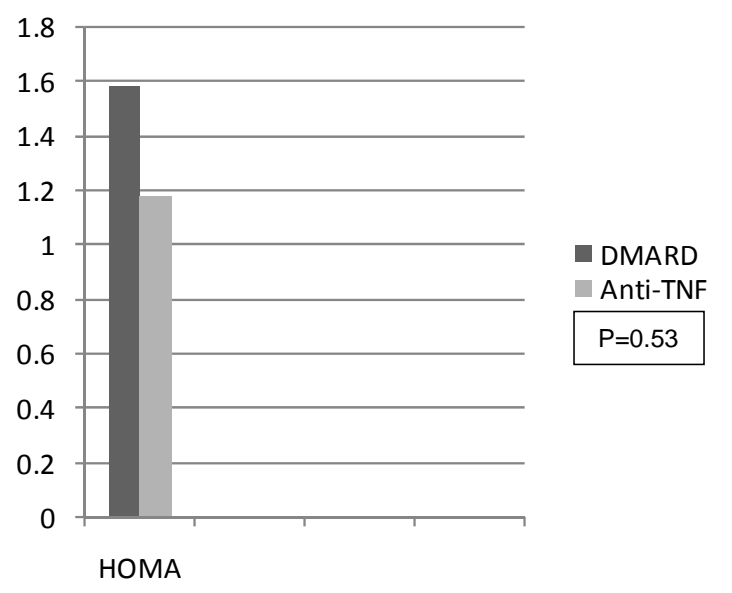

Figure 1. HOMA comparison between the two groups: DMARD vs anti-TNF.

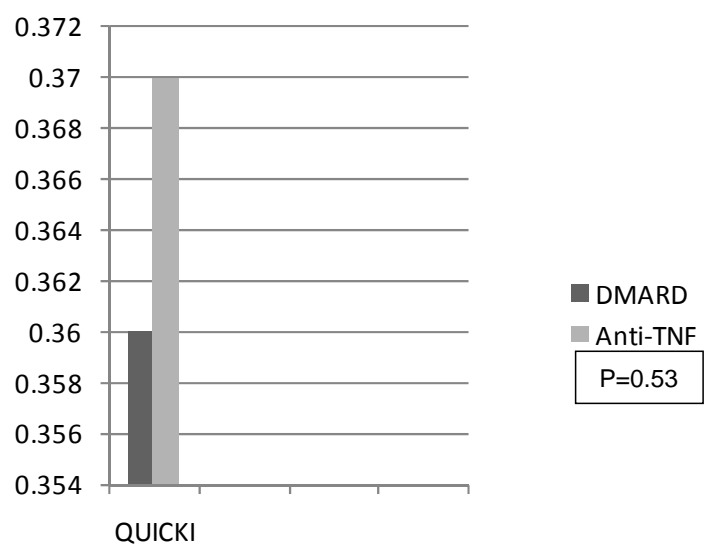

Figure 2. QUICKI comparison between the two groups: DMARD vs anti-TNF. 
changes in their HOMA and QUICKI index, in spite of the anti-TNF therapy. We should point out the difference in our study as far as patient selection was concerned, as those with steroid and those that were active were excluded, but we found that there was no major difference in the HOMA and QUICKI of both treatment groups. Rosenvinge et al. [19] did also not observe any decrease in resistance to insulin, even though they used Adalimumab, unlike our study in which most patients of the antiTNF therapy group were given Etanercept.

We have come across results that differ to ours. In a study carried out in Spain [17], 27 active patients with RA with an average DAS 28 of 4.43 were examined, whose seric insulin level and HOMA index were reduced after being administered Infliximab. A Turkish group headed by Oguz [20] included seven patients with RA who were treated with Infliximab, whose seric insulin level was reduced, as was their resistance to insulin by HOMA, with a statistically substantial difference. Results that favor a substantial decrease in resistance to insulin were also obtained in a group of patients with activity of the disease in China, with the use of Infliximab [21].

The particular aspect of our study was that we directly compared the effect of anti-TNF therapy with non-biological DMARDs, removing confusing factors that were definitely involved with resistance to insulin, unlike other studies that have examined this phenomenon, as they included patients who were obese, active, taking steroids, with dyslipidemia, etc., the only difference in our two groups of patients being the anti-TNF therapy.

There is no doubt that the limitation of our study is the size of the sample and this may explain the absence of substantial differences, so prospective, multi-centric and longitudinal studies need to be carried out to establish the actual impact of this type of treatment.

\section{REFERENCES}

[1] J. Zwerina, K. Redlich, G. Schett and J. S. Smolen, "Pathogenesis of Rheumatoid Arthritis: Targeting Cytokines," Annals of the New York Academy of Sciences, Vol. 1051, 2005, pp. 716-729. doi:10.1196/annals.1361.116

[2] S. Van Doornum, G. McColl and I. P. Wicks, "Accelerated Atherosclerosis: An Extraarticular Feature of Rheumatoid Arthritis?" Arthritis \& Rheumatism, Vol. 46, No. 4, 2002, pp. 862-873. doi:10.1002/art.10089

[3] M. Boers, B. Dijkmans, S. Gabriel, H. Maradit-Kremers, J. O'Dell and T. Pincus, "Making an Impact on Mortality in Rheumatoid Arthritis: Targeting Cardiovascular Comorbidity," Arthritis \& Rheumatism, Vol. 50, No. 6, 2004, pp. 1734-1739. doi:10.1002/art.20306

[4] G. Paolisso, G. Valentini, D. Guigliamo, G. Mavrazzo, R. Tirri, M. Gallo, et al., "Evidence for Peripheral Impaired Glucose Handling in Patients with Connective Tissue
Diseases," Metabolism, Vol. 40, 1991, pp. 902-907. doi:10.1016/0026-0495(91)90064-4

[5] K. L. G. Svenson, T. Pollare, H. Lithell and R. Hallgren, "Impaired Glucose Handling in Active Rheumatoid Arthritis: Relationship to Peripheral Insulin Resistance," Metabolism, Vol. 37, 1998, pp. 125-130.

doi:10.1016/S0026-0495(98)90005-1

[6] G. La Montagna, F. Cacciapuoti, R. Buono, D. Manzella, G. Mennillo, A. Arciello, G. Valentini and G. Paolisso, "Insulin Resistance Is and Independent Risk Factor for Atherosclerosis in Rheumatoid Arthritis," Diabetes and Vascular Disease Research, Vol. 4, No. 2, 2007, pp. 130135. doi:10.3132/dvdr.2007.031

[7] J. P. Despres, B. Lamarche and P. Mauriege, "Hyperinsulinemia as an Independent Risk Factor for Ischemic Heart Disease," New England Journal of Medicine, Vol. 334, No. 15, 1996, pp. 952-957. doi:10.1056/NEJM199604113341504

[8] P. Libby, G. Sukhova, R. T. Lee and Z. S. Galis, "Cytokines Regulate Vascular Functions Related to Stability of the Atherosclerotic Plaque," Journal of Cardiovascular Pharmacology, Vol. 25, Suppl 2, 1995, pp. S9-S12. doi:10.1097/00005344-199500252-00003

[9] C. Book, T. Saxne and L. T. Jacobsson, "Prediction of Mortality in Rheumatoid Arthritis Based on Disease Activity Markers," Journal of Rheumatology, Vol. 32, No. 3, 2005, pp. 430-434.

[10] S. Wallberg-Jonsson, H. Johansson, M. L. Ohman and S. Rantapaa-Dahlqvist, "Extent of Inflammation Predicts Cardiovascular Disease and Overall Mortality in Seropositive Rheumatoid Arthritis. A Retrospective Cohort Study from Disease Onset," Journal of Rheumatology, Vol. 26, No. 12, 1999, pp. 2562-2571

[11] G. S. Hotamisligil and B. M. Spiegelman, "Tumor Necrosis Factor Alpha: A Key Component of the ObesityDiabetes Link," Diabetes, Vol. 43, No. 11, 1994, pp. 1271-1278. doi:10.2337/diabetes.43.11.1271

[12] G. S. Hotamisligil, P. Arner, J. F. Caro, R. L. Atkinson and B. M. Spiegelman, "Increased Adipose Tissue Expression of Tumor Necrosis Factor-Alpha in Human Obesity and Insulin Resistance," Journal of Clinical Investigation, Vol. 95, No. 5, 1995, pp. 2409-2415. doi:10.1172/JCI117936

[13] M. Saghizadeh, J. M. Ong, W. T. Garvey, R. R. Henry and P. A. Kern, "The Expression of TNF Alpha by Human Muscle. Relationship to Insulin Resistance," Journal of Clinical Investigation, Vol. 97, No. 4, 1996, pp. 11111116. doi:10.1172/JCI118504

[14] G. S. Hotamisligil, N. S. Shargill and B. M. Spiegelman, "Adipose Expression of Tumor Necrosis Factor Alpha: Direct Role in Obesity-Linked Insulin Resistance," Science, Vol. 259, No. 5091, 1993, pp. 87-91. doi:10.1126/science. 7678183

[15] T. Saxne, M. A. Palladino Jr., D. Heinegard, N. Talal and F. A. Wollheim, "Detection of Tumor Necrosis Factor Alpha But Not Tumor Necrosis Factor Beta in Rheumatoid Arthritis Synovial Fluid and Serum," Arthritis \& Rheumatism, Vol. 31, 1988, pp. 1041-1045.

doi:10.1002/art.1780310816 
[16] D. N. Kiortsis, A. K. Mavridis, S. Vasakos, S. N. Nikas and A. A. Drosos, "Effects of Infliximab Treatment on Insulin Resistance in Patients with Rheumatoid Arthritis and Ankylosing Spondylitis," Annals of the Rheumatic Diseases, Vol. 64, No. 5, 2005, pp. 765-766. doi:10.1136/ard.2004.026534

[17] M. A. Gonzalez-Gay, J. M. De Matias, C. Gonzalez-Juanatey, C. Garcia-Porrua, A. Sanchez-Andrade, J. Martin and J. Llorca, "Anti-Tumor Necrosis Factor-Alpha Blockade Improves Insulin Resistance in Patients with Rheumatoid Arthritis," Clinical and Experimental Rheumatology, Vol. 24, No. 1, 2006, pp. 83-86.

[18] F. C. Arnett, S. M. Edworthy, D. A. Bloch, D. J. McShane, J. F. Fries, N. S. Cooper, L. A. Healey, S. R. Kaplan, M. H. Liang, H. S. Luthra, et al., "The American Rheumatism Association 1987 Revised Criteria for the Classification of Rheumatoid Arthritis," Arthritis \&

\section{List of Abbreviations}

ACR-American college of rheumatology

RA-Rheumatoid arthritis

TNF_-Tumor necrosis factor

DMARD_Disease-modifying anti-rheumatic drugs
Rheumatism, Vol. 31, No. 3, 1988, pp. 315-324. doi:10.1002/art.1780310302

[19] A. Rosenvinge, R. Krogh-Madsen, B. Baslund and B. K. Pedersen, "Insulin Resistance in Patient with Rheumatoid Arthritis: Effect of Anti-TNFalpha Therapy," Scandinavian Journal of Rheumatology, Vol. 36, No. 2, 2007, pp. 91-96. doi:10.1080/03009740601179605

[20] F. M. Oguz, A. Oguz and M. Uzunlulu, "The Effect of Infliximab Treatment on Insulin Resistance in Patients with Rheumatoid Arthritis," Acta Clinica Belgica, Vol. 62, No. 4, 2007, pp. 218-222.

[21] L. S. Tam, B. Tomlinson, T. T. Chu, T. K. Li and E. K. Li, "Impact of TNF Inhibition on Insulin Resistance and Lipids Levels in Patients with Rheumatoid Arthritis," Clinical Rheumatology, Vol. 26, No. 9, 2007, pp. 1495-1498. doi:10.1007/s10067-007-0539-8

HOMA-Homeostasis Model Assessment QUICKI-Insulin Sensitivity Check Index DAS 28-Disease activity score 28

BMI-Body mass index 